\title{
Meso-tetraphenylporphyriniron(iii) chloride catalyzed oxidation of aniline and its substituents by magnesium monoperoxyphthalate in aqueous acetic acid medium
}

\author{
Raja Manickam, Karunakaran Kulandaivelu* \\ Sona College of Technology, Department of Chemistry, Salem - 636005, Tamilnadu, India \\ "Corresponding author:drkk@sonatech.ac.in
}

\begin{abstract}
The catalytic properties of the first generation catalyst meso-tetraphenylporphyriniron(III) chloride and magnesium monoperoxyphthalate (MMPP) as oxidant have been studied in the oxidation of aniline and its substituents in acetic acid medium. The thermodynamic parameters for the oxidation have been determined and discussed. It confirms the Exner relationship (only at the low range of temperatures) and also some of the activation parameters to the isokinetic relationships. The magnesium monoperoxyphthalate oxidation with 18 ortho- meta- and para-substituted anilines fulfills with isokinetic relationship but not to any of the linear free energy relationships. The reaction mechanism and the rate law were proposed.
\end{abstract}

Keywords: Aniline oxidation, kinetics, mechanism, magnesium monoperoxyphthalate, mesotetraphenylporphyriniron(III) chloride, catalyst.

\section{INTRODUCTION}

The cytochrome P450 is a large group of enzymes. The most common reaction catalyzed by cytochromes $\mathrm{P} 450$ is a monooxygenase reaction. For cytochrome P-450 the model catalyst metalloporphyrins could be used as the intermediate of oxygen carrier in biological systems. Metalloporphyrins have been widely used as catalysts for various oxidation reactions1-5. The importance of metalloporphyrins is due to their catalytic, electrocatalytic, and electron-transfer properties, which are directly related to the stabilization of the transition metal ion in high oxidation states by the formation of $\mathrm{M}^{\mathrm{IV}}=\mathrm{O}$ - and $\mathrm{M}^{\mathrm{V}}=\mathrm{O}$ - like species ${ }^{6}$.The contribution of heme in these oxidation processes aggravated chemists to turn away from these naturally occurring catalysts and operate them into industrial processes. Heme itself is very unstable in oxidations, and that is why the more robust metallo-tetraarylporphyrins were introduced. These complexes can catalyze the oxidation of aniline. Metalloporphyrin iron complexes have been the subject as a catalyst in a number of findings ${ }^{7,8}$ and in the present study the first generation catalyst meso-tetraphenylporphyriniron(III) chloride $(5,10,15,20$-tetraphenyl-21h,23h-porphineiro$\mathrm{n}$ (III) chloride) is added as a catalyst in the selective oxidation of aniline. Many mechanistic studies ${ }^{9-11}$ have revealed that halogenated metalloporphyrin complexes are excellent catalysts for complicated oxidations with high selectivity. The iron complexes with meso-tetraphenyl groups are considered as a model of the natural ironporphyrins due to their constructive properties such as catalytic and semi-conducting properties. Among the oxygen donors, towards oxidation, magnesium monoperoxyphthalate (MMPP) was recently found to be a very efficient oxidant ${ }^{12-14}$. The kinetics of the oxidation of anilines by a variety of oxidants has been reported ${ }^{15-19}$ and few of them authenticate Hammet equation.

\section{EXPERIMENTAL}

\section{Materials and methods}

The catalyst meso-tetraphenylporphyriniron(III) chloride and magnesium monoperoxyphthalate (Sigma Aldrich) was used as received. All the chemicals and solvents used were of the analytical grade (Merck, India). Aniline was redistilled before use. Acetic acid was purified by redistillation. ortho- meta- and para- substituents of aniline were redistilled / recrystallized before use. All the reagents were freshly prepared just before the reactions were carried out. Aqueous solution of magnesium monoperoxyphthalate was prepared fresh using double distilled water and standardized iodometrically. Kinetic studies were made with aniline by varying the concentration of aniline, magnesium monoperoxyphthalate, meso-tetraphenylporphyriniron(III) chloride, acetic acid, $\mathrm{H}^{+}$and by varying temperature. All the reactions were carried out in a thermostat and the temperature was controlled to $\pm 0.1^{\circ} \mathrm{C}$. The reaction rate was found by estimating the amount of the unconsumed magnesium monoperoxyphthalate iodometrically up to $80 \%$ of completion of the reaction. The rate constants $\left(\mathrm{k}_{\mathrm{obs}}\right)$ were determined by the least square slopes of the linear plots of log[magnesium monoperoxyphthalate] and time. Replicate runs showed that the rate constants for the oxidation reactions were reproducible within $\pm 3 \%$. The reaction was also carried out using acrylonitrile to find the presence of free radical mechanism. The oxidation reactions of meta- and para-substituents of aniline were studied at different temperatures via 297, 302, 307, 312 and $317 \mathrm{~K}$ to evaluate various thermodynamic parameters.

From the Eyrings equation ${ }^{19}$ the thermodynamic parameters, enthalpy of activation and entropy of activation were found out from the expression $\mathrm{k}_{\mathrm{obs}}=\left(\mathrm{k}_{\mathrm{b}} \mathrm{T} / \mathrm{h}\right) \exp ^{-\Delta \mathrm{G} \# / \mathrm{RT}}$

Where $\mathrm{k}_{\mathrm{b}}$ is Boltzmann's constant, $\mathrm{T}$ is the temperature in Kelvin, $\mathrm{h}$ is plank's constant, $\mathrm{R}$ is the gas constant, $\Delta \mathrm{G}^{\#}$ is the activation of Gibbs free energy, $\Delta \mathrm{H}^{\#}$ is the enthalpy of activation and $\Delta \mathrm{S}^{\#}$ is the entropy of activa- 
tion. $\Delta G^{\#}$ and energy of activation $\left(E_{a}\right)$ can be calculated from the following expressions respectively. $\Delta \mathrm{G}^{\#}=\Delta \mathrm{H}^{\#}-\mathrm{T} \Delta \mathrm{S}^{\#}$ and $\mathrm{E}_{\mathrm{a}}=\Delta \mathrm{H}^{\#}+\mathrm{RT}$

Various thermodynamic parameters were found out and were recorded.

\section{Stoichiometry and product analysis}

The stoichiometry of the reaction was found out by doing several sets of experiments by varying [magnesium monoperoxyphthalate] in the range of $0.1-1.5 \mathrm{M}$ $([$ substrate $]=0.1 \mathrm{M}$, [catalyst $]=1.4 \times 10^{-6} \mathrm{M}$, acetic aci$\mathrm{d}$ :water $=50: 50,\left[\mathrm{H}^{+}\right]=0.2 \mathrm{~N}$, temperature $=300 \mathrm{~K}$ ). The estimation of the unconsumed magnesium monoperoxyphthalate showed that the stoichiometry of the reaction was found to be in the ratio of 1:2 (magnesium monoperoxyphthalate: aniline).The oxidation product was confirmed using TLC. Under the pseudo-first order condition [aniline] $>>$ [magnesium monoperoxyphthalate] in acetic acid medium, the product obtained was followed spectrophotometrically at $429 \mathrm{~nm}$. The $\lambda_{\max }$ of azobenzene was confirmed by comparing with that of the authentic sample in aqueous acetic acid medium. This was in agreement with the literature value ${ }^{\mathbf{1 9}}$. The melting point of the product obtained is $68^{\circ} \mathrm{C}$ which is in agreement with literature value $\mathrm{e}^{\mathbf{1 6 , 2 0}}$.

\section{RESULTS AND DISCUSSION}

\section{Effect of aniline concentration on oxidation rate}

The value of $\mathrm{k}_{\mathrm{obs}}$ was calculated for different concentration of aniline at constant concentrations of catalyst, magnesium monoperoxyphthalate, and $\mathrm{H}_{2} \mathrm{SO}_{4}$ in acetic acid medium, the increase in concentration of substrate (aniline) increased the reaction rate. The plot (Figure 1) of $\log \mathrm{k}_{\mathrm{obs}} v s \log [$ aniline] was found to be a straight line with slope 2 representing the second order dependence of reaction rate on substrate.

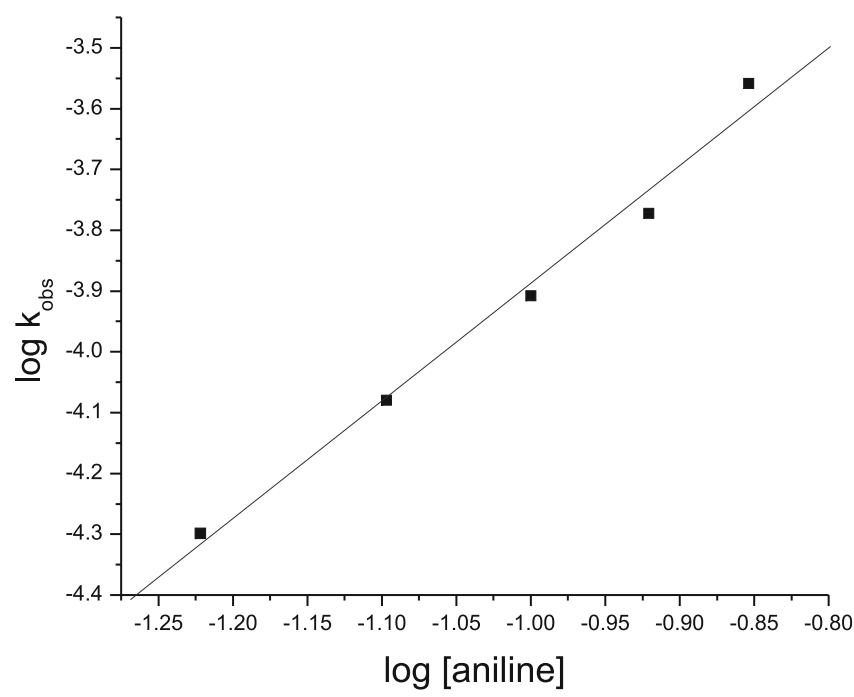

Figure 1. Plots of $\log \mathrm{k}_{\mathrm{obs}}$ versus $\log$ [aniline] and $1 / \mathrm{k}_{\mathrm{obs}}$ versus $1 /$ [aniline] for the oxidation of aniline by magnesium monoperoxyphthalate catalysed by mesotetraphenylporphyriniron(III) chloride. [oxidant] = $0.005 \mathrm{M}$, [catalyst] $=8 \times 10^{-6} \mathrm{M}$, acetic acid:water $=$ $50: 50,\left[\mathrm{H}^{+}\right]=0.4 \mathrm{M}$, temperature $=302 \mathrm{~K}$
Effect of magnesium monoperoxyphthalate concentration on the oxidation rate

The increase in the concentration of magnesium monoperoxyphthalate keeping other parameters at constant values did not affect the apparent rate constant of the reaction (Table 1). The first order plot of log[magnesium monoperoxyphthalate] $v s$ time was found to be linear. The pseudo first order rate constants found from the plots hanged unaltered by the change in [magnesium monoperoxyphthalate] confirmed the first order dependence of the reaction rate on magnesium monoperoxyphthalate.

Table 1. Pseudo-first order rate constants for the oxidation of aniline by varying [magnesium]

\begin{tabular}{|l|c|}
\hline [oxidant] $(\mathrm{M})$ & $10^{5} \mathrm{k}_{\mathrm{obs}}\left(\mathrm{s}^{-1}\right)$ \\
\hline 0.003 & 10.77 \\
\hline 0.004 & 10.77 \\
\hline 0.005 & 10.81 \\
\hline 0.006 & 10.80 \\
\hline 0.007 & 10.85 \\
\hline
\end{tabular}

[substrate $]=0.1 \mathrm{M}$, [catalyst $]=9 \times 10^{-6} \mathrm{M}$, acetic acid-water $=50: 50$, $\left[\mathrm{H}^{+}\right]=0.4 \mathrm{M}$, temperature $=302 \mathrm{~K}$

\section{Effect of variation of $\mathbf{h}^{+}$concentration}

The rate of the reaction decreased with the increase in $\mathrm{H}_{2} \mathrm{SO}_{4}$ concentration keeping other parameter values constant. The plot (Figure 2) $\log \mathrm{k}_{\mathrm{obs}}$ vs $\log \left[\mathrm{H}^{+}\right]$gave a straight line with unit slope indicating a first order dependence on $\left[\mathrm{H}^{+}\right]$.

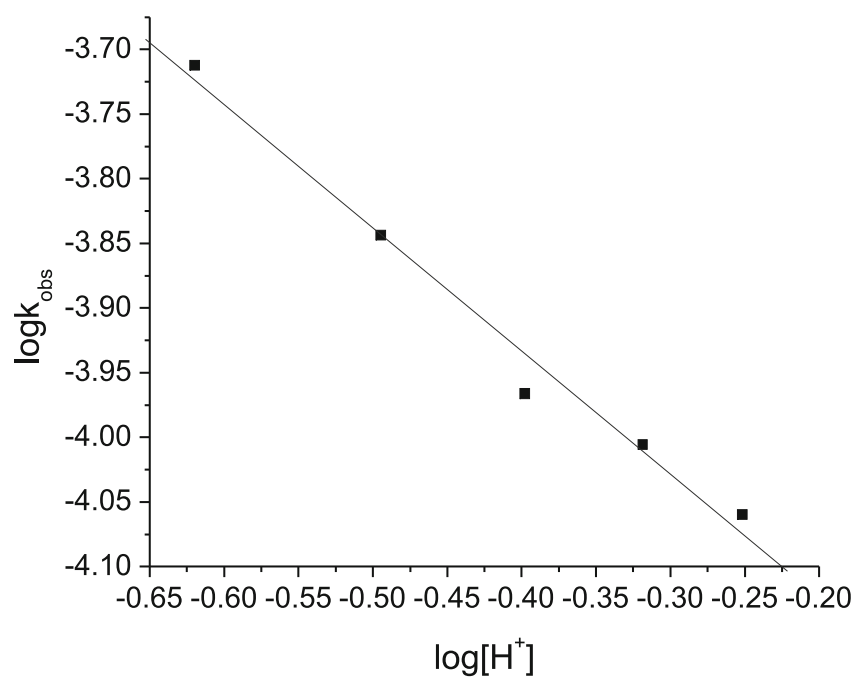

Figure 2. Plot of $\log \mathrm{k}_{\mathrm{obs}}$ versus $\log \left[\mathrm{H}^{+}\right]$for the oxidation of aniline by magnesium monoperoxyphthalate catalysed by meso-tetraphenylporphyriniron(III) chloride [substrate] $=0.1 \mathrm{M}$, [oxidant] $=0.005 \mathrm{M}$, [catalyst $]$ $=8 \times 10^{-6} \mathrm{M}$, acetic acid:water $=50: 50$, temperature $=302 \mathrm{~K}$

Effect of meso-tetraphenylporphyriniron(iii) chloride concentration on the oxidation rate

There is no reaction of the oxidation of aniline by magnesium monoperoxyphthalate but when catalysed by meso-tetraphenylporphyriniron(III) chloride the reaction rate increases at a remarkable rate. The increase in the concentration of the catalyst enhances the rate of the reaction. But the plot (Figure 3 ) of $\log \mathrm{k}_{\mathrm{obs}} v s \log$ [catalyst] 


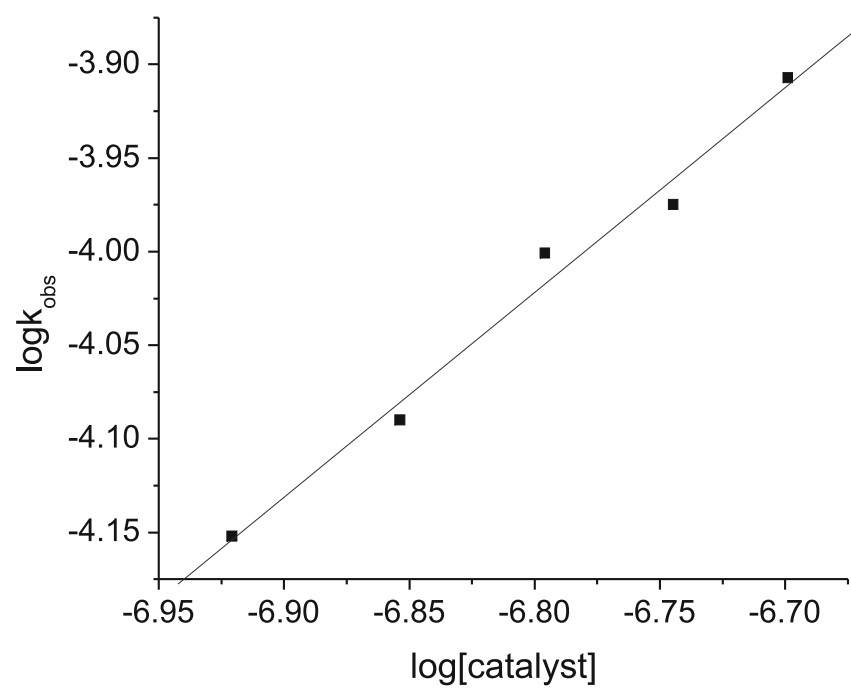

Figure 3. Plot of $\log \mathrm{k}_{\mathrm{obs}}$ versus $\log [$ meso-tetraphenylporphyriniron(III) chloride] for the oxidation of aniline by magnesium monoperoxyphthalate catalysed by meso-tetraphenylporphyriniron(III) chloride [substrate $]=0.1 \mathrm{M}$, [oxidant $]=0.005 \mathrm{M}$, acetic acid : water $=50: 50,\left[\mathrm{H}^{+}\right]=0.4 \mathrm{M}$, temperature $=302 \mathrm{~K}$

was found to be linear with a unit slope indicating a first order dependence with respect to the catalyst.

\section{Effect of temperature on the oxidation rate}

The oxidation of aniline was studied at different temperatures $297 \mathrm{~K}$ to $317 \mathrm{~K}$ maintaining the concentration of substrate, oxidant, $\mathrm{H}^{+}$, solvent and catalyst constant. The plot of $\operatorname{lnk}_{\mathrm{obs}} / \mathrm{T}$ vs $1 / \mathrm{T}$ (Figure 4) was found to be linear.

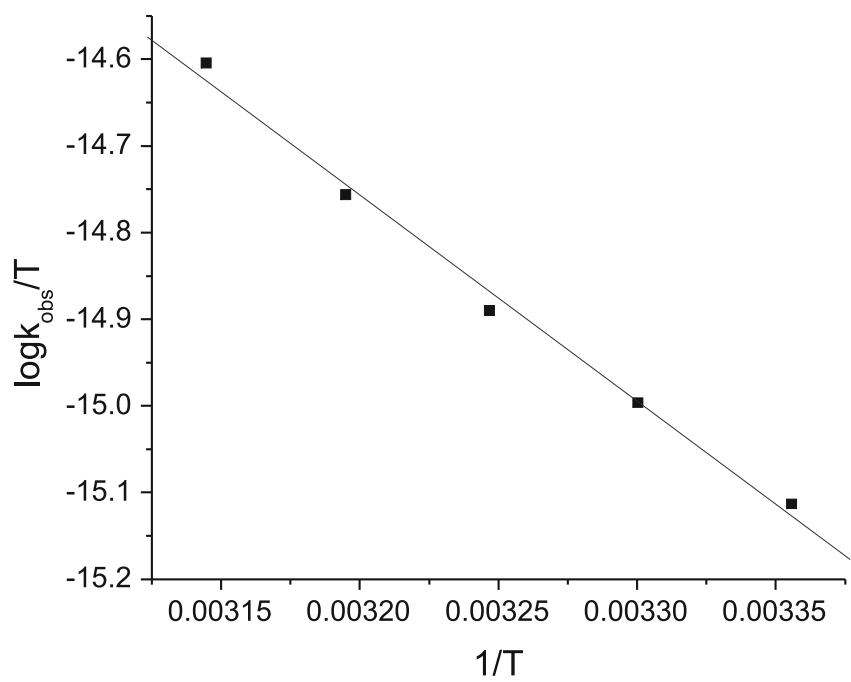

Figure 4. Plot of $\operatorname{lnk}_{\mathrm{obs}} / \mathrm{T}$ versus $1 / \mathrm{T}$ for the oxidation of aniline by magnesium monoperoxyphthalate catalysed by meso-tetraphenylporphyriniron(III) chloride [substrate $]=0.1 \mathrm{M}$, [oxidant $]=0.005 \mathrm{M}$, [catalyst $]=$ $8 \times 10^{-6}$, acetic acid : water $=50: 50,\left[\mathrm{H}^{+}\right]=0.4 \mathrm{M}$

\section{Effect of dielectric constant}

To fix on the result of the dielectric constant (polarity) of the medium, the oxidation was carried out by maintaining the concentration of aniline, magnesium monoperoxyphthalate, catalyst and temperature as constant and varying the aqueous acetic acid mixtures of various compositions (Table 2). The above results clearly reveal that the rate of the reaction increases with a decrease in percentage of acetic acid, i.e. with
Table 2. Pseudo-first order rate constants for the oxidation of aniline by magnesium monoperoxyphthalate catalysed by meso-tetraphenylporphyriniron(III) chloride in different acetic acid

\begin{tabular}{|l|c|c|}
\hline$\%$ Acetic acid & $\mathrm{D}$ & $10^{5} \mathrm{k}_{\mathrm{obs}}\left(\mathrm{s}^{-1}\right)$ \\
\hline 70 & 27.90 & 89.42 \\
\hline 60 & 35.14 & 33.23 \\
\hline 50 & 42.37 & 10.71 \\
\hline 40 & 49.60 & 6.65 \\
\hline 30 & 56.83 & 2.92 \\
\hline
\end{tabular}

[substrate] $=0.1 \mathrm{M}$, [oxidant] $=0.005 \mathrm{M}$, [catalyst $]=8 \times 10^{6} \mathrm{M}$, $\left[\mathrm{H}^{+}\right]=0.4 \mathrm{M}$, temperature $=302 \mathrm{~K}$

decreasing the dielectric constant (D) or polarity of the medium. This directs to the conclusion that there is a charge development in the intermediate state suggesting a polar (ionic) mechanism. Fig. 5 shows the UV spectrum at early stages and final stages of the oxidation reaction. At the initial stages of the reaction a new peak at 717 $\mathrm{nm}$ appeared, slowly diminishing and vanishing at the final stages of the reaction. This may be due to the formation of an intermediate from which products were formed. Simultaneously at $429 \mathrm{~nm}$ a peak appeared and was stable till the end of the reaction. The may be due to the formation of the product which was in agreement with literature value ${ }^{19}$ ( $429 \mathrm{~nm}$ is the $\lambda_{\max }$ of azobenzene in acetic acid medium).

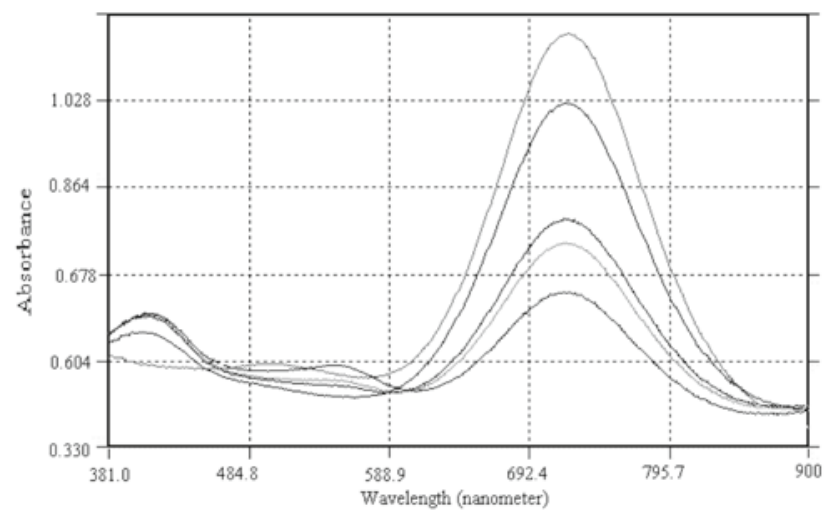

Figure 5. UV spectrum showing a probable formation of intermediate complex in oxidation of aniline by magnesium monoperoxyphthalate catalysed by mesotetraphenylporphyriniron(III) chloride [substrate] = $0.1 \mathrm{M}$, [ oxidant $]=0.005 \mathrm{M}$, $[$ catalyst $]=8 \times 10^{-6} \mathrm{M}$, acetic acid:water $=50: 50$, temperature $=302 \mathrm{~K},\left[\mathrm{H}^{+}\right]=$ $0.4 \mathrm{M}$

\section{Substituents effect on oxidation rate}

The oxidation of aniline and $o-\mathrm{OCH}_{3}, m-\mathrm{OCH}_{3}, p-$ $\mathrm{OCH}_{3}, o-\mathrm{CH}_{3}, m-\mathrm{CH}_{3}, p-\mathrm{CH}_{3}, o-\mathrm{Cl}, m-\mathrm{Cl}, p-\mathrm{Cl}, o-\mathrm{Br}$, $m-\mathrm{Br}, p-\mathrm{Br}, o-\mathrm{F}, m-\mathrm{F}, p-\mathrm{F}, o-\mathrm{NO}_{2}, m-\mathrm{NO}_{2}, p-\mathrm{NO}_{2}$ anilines in the presence of catalyst were conducted under the pseudo-first order conditions at various temperatures 297 $\mathrm{K}, 302 \mathrm{~K}, 307 \mathrm{~K} 312 \mathrm{~K}$, and $317 \mathrm{~K}$ to determine various thermodynamic parameters. The various thermodynamic parameters $\Delta \mathrm{H}^{\#}$ and $\Delta \mathrm{S}^{\#}$ were determined and tabulated (Table 3). The findings in Table 3 show that the oxidation is neither isoenthalphic nor isoentropic but proves the isokinetic relationship of the compensation law.

Since the reactions are of ion-polar, it is expected that the entropy of the activated complex for all the anilines should be nearly the same order of magnitude. But due to the variation in the polarity of different anilines, $\Delta \mathrm{S}^{\#}$ may be different for different anilines ${ }^{22}$, as observed in 
Table 3. Pseudo-first order rate constants for meso-tetraphenylporphyriniron(III) chloride catalyzed $m$-chloroperbenzoic acid oxidation of meta- and para- substituted anilines at different temperatures, thermodynamic and activation parameters

\begin{tabular}{|c|c|c|c|c|c|c|c|}
\hline \multirow{2}{*}{$\begin{array}{l}\text { Aniline } \\
\text { substituents }\end{array}$} & \multicolumn{5}{|c|}{$10^{5} \mathrm{k}_{\text {obs }}\left(\mathrm{s}^{-1}\right)$} & \multirow{2}{*}{$\begin{array}{c}\Delta \mathrm{H}^{\#} \\
\mathrm{~kJ} \\
\mathrm{~mol}^{-1}\end{array}$} & \multirow{2}{*}{$\begin{array}{l}-\Delta \mathrm{S}^{\#} \\
\mathrm{~J} \mathrm{~K}^{-1} \\
\mathrm{~mol}^{-1}\end{array}$} \\
\hline & $297 \mathrm{~K}$ & $302 \mathrm{~K}$ & $307 \mathrm{~K}$ & $312 \mathrm{~K}$ & $317 \mathrm{~K}$ & & \\
\hline $\mathrm{o}-\mathrm{OCH}_{3}$ & 13.2 & 16.03 & 21.91 & 28.2 & 37.56 & 39.29 & -187.84 \\
\hline $\mathrm{o}-\mathrm{CH}_{3}$ & 8.68 & 9.52 & 11.37 & 11.79 & 13.87 & 15.58 & -270.59 \\
\hline $\mathrm{O}-\mathrm{Cl}$ & 40.71 & 75.92 & 113.04 & 156.85 & 308.91 & 72.77 & -65.52 \\
\hline $\mathrm{o}-\mathrm{Br}$ & 31.79 & 57.06 & 112.37 & 174.61 & 287.02 & 77.36 & -51.07 \\
\hline$O-F$ & 14.2 & 20.33 & 31.82 & 41.05 & 59.86 & 53.92 & -37.76 \\
\hline $\mathrm{o}-\mathrm{NO}_{2}$ & 10.33 & 21.29 & 46.95 & 88.64 & 154.2 & 105.28 & 32.13 \\
\hline$m-\mathrm{OCH}_{3}$ & 5.10 & 11.35 & 33.95 & 72.1 & 224.46 & 145.80 & 161.27 \\
\hline$m-\mathrm{CH}_{3}$ & 7.47 & 8.59 & 9.80 & 11.85 & 12.69 & 19.23 & -259.57 \\
\hline$m-\mathrm{Cl}$ & 7.29 & 27.14 & 46.14 & 108.84 & 428.13 & 147.66 & 177.63 \\
\hline$m-\mathrm{Br}$ & 14.35 & 19.08 & 22.75 & 29.58 & 34.45 & 32.00 & -211.06 \\
\hline$m-\mathrm{F}$ & 7.62 & 13.34 & 20.57 & 31.69 & 61.22 & 79.78 & -56.75 \\
\hline$m-\mathrm{NO}_{2}$ & 15.27 & 22.23 & 31.08 & 41 & 51.5 & 45.44 & -165.32 \\
\hline$p-\mathrm{OCH}_{3}$ & 8.70 & 14.36 & 44.12 & 94.92 & 312.04 & 139.89 & 144.79 \\
\hline$p-\mathrm{CH}_{3}$ & 2.84 & 3.47 & 4.03 & 4.90 & 5.70 & 24.95 & -248.35 \\
\hline$p-\mathrm{Cl}$ & 7.73 & 15.83 & 26.33 & 40.20 & 71.14 & 82.23 & -47.29 \\
\hline$p-\mathrm{Br}$ & 9.61 & 13.24 & 16.59 & 24.07 & 31.39 & 44.17 & -173.83 \\
\hline$p-F$ & 3.64 & 4.64 & 7.88 & 9.82 & 16.3 & 56.48 & -141.02 \\
\hline$p-\mathrm{NO}_{2}$ & 18.24 & 39.59 & 69.74 & 188.21 & 320.22 & 112.37 & 60.28 \\
\hline $\mathrm{H}$ & 8.17 & 9.33 & 10.55 & 12.25 & 14.49 & 19.79 & -257.04 \\
\hline
\end{tabular}

[substrate] $=0.1 \mathrm{M},[$ oxidant $]=0.005 \mathrm{M},[$ catalyst $]=8 \times 10^{-6} \mathrm{M}$, acetic acid water $=50: 50,\left[\mathrm{H}^{+}\right]=0.4 \mathrm{M}$

the present findings. But the isokinetic relationship exists. The plot of activation enthalpy versus activation entropy follows a straight line as shown in Figure 6.

Isokinetic temperature is the temperature at which all the compounds of the series react equally at same rate $^{23}$ and was determined from the following equation $\Delta \mathrm{H}^{\#}=\Delta \mathrm{H}^{\mathrm{o}}+\beta \Delta \mathrm{S}^{\#}$

Where $\beta$ is the isokinetic temperature and it was found to be $334.9 \mathrm{~K}$ which is lesser than the experimental temperature. The function of the isokinetic relationship reveals that a common mechanism is working in all the aniline oxidation reactions.

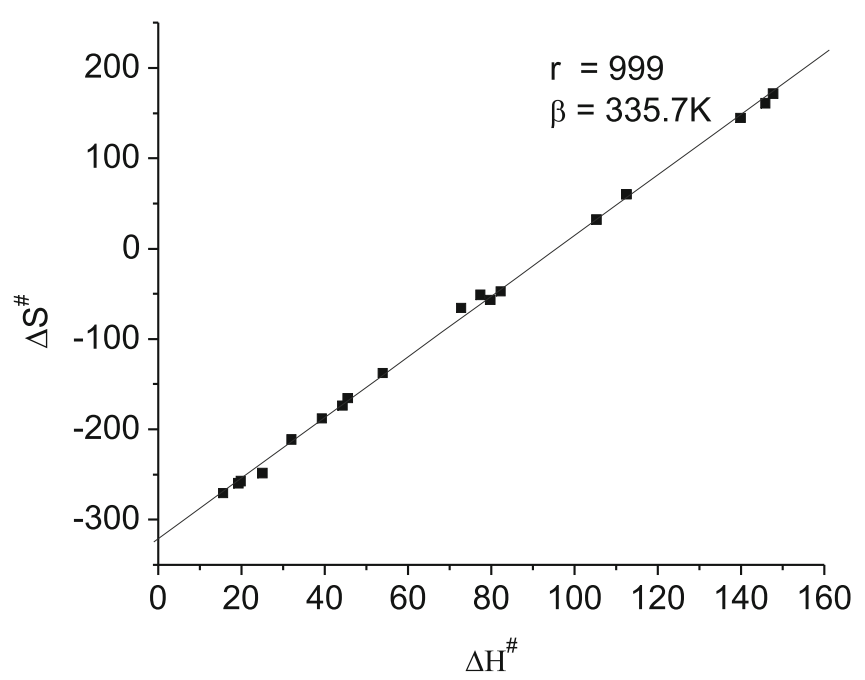

Figure 6. Isokinetic plot for the meso-tetraphenylporphyriniron(III) chloride catalysed oxidation of anilines by magnesium monoperoxyphthalate
The values of the free energy of the activation of the reactions were found to be more or less the same. This is due to the fact that at the isokinetic temperature the change of the substituent has no influence on the free energy of activation. If the isokinetic temperature is infinite in isoentropic oxidation reactions only the enthalpy of activation finalizes the reactivity and if the isokinetic temperature is zero in isoenthalpic oxidation reactions only the entropy of activation finalizes the reactivity ${ }^{\mathbf{1 8}}$.

The Exner relationship (Figure 7) logarithmic relationship between the rates at two temperatures is applicable only to a small range of temperatures $(5 \mathrm{~K}-10 \mathrm{~K})$ beyond

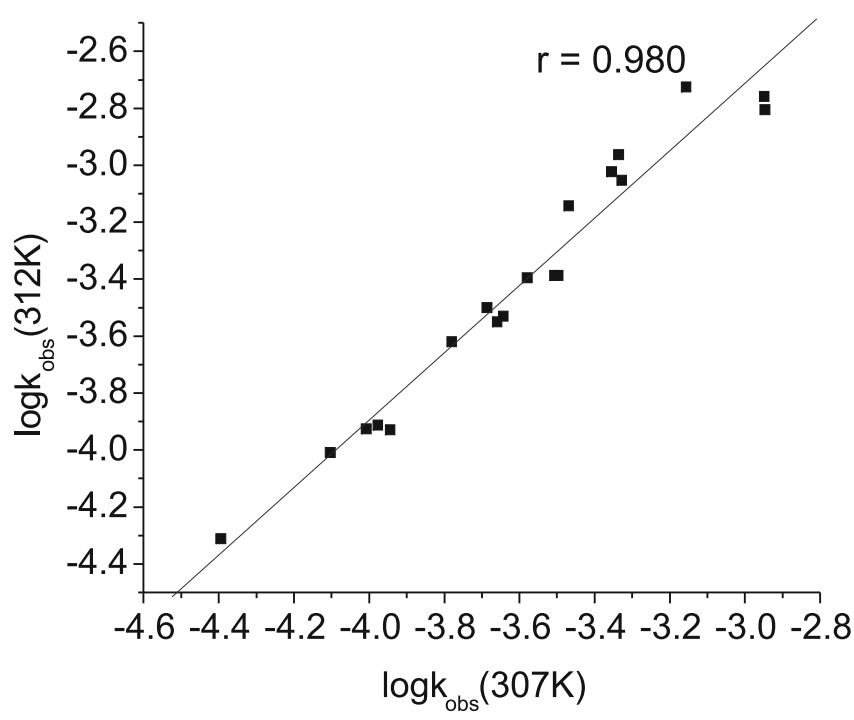

Figure 7. Exner plot for the meso-tetraphenylporphyriniron(III) chloride catalysed oxidation of anilines by magnesium monoperoxyphthalate 
which the Exner relationship is not satisfactory. This gives uncertainty to the parameters that were calculated.

\section{Structure-reactivity correlation}

The outcome in Table 3 gives the information that the $\Delta \mathrm{G}^{\#}$ values vary with the substrate. This may be due to the dissimilarity in polarity of various anilines. So the obtained rate constants show deviation with substutients. Negative entropy of activation gives the conformation the complex formed is an associate type and a greater degree of charge in the transition state than the initial state $^{15}$. The rate data obtained was also unsuccessful in proving the typical Hammet equation $\log \mathrm{k}_{\mathrm{obs}} v s \sigma$ is a dispersed gram, a sensitive plot at the temperatures studied. Literature study ${ }^{23}$ reveals that the correlation obtained with it was poor as the substituents were conjugated with the reaction centre, where the problem arose with anilinium ions, where a lone pair of electrons on the $\mathrm{NH}_{2}$ group could be delocalized into substituents such as $p-\mathrm{NO}_{2}$

From (table 3) correlation of oxidation rates of metaand para- substituted anilines with unit parameters and double substituent parameter equations were also found to be ineffective. The possible reason for the lack of free energy relationship is that the isokinetic tempe-<smiles>COC(=O)c1ccccc1C(=O)OO</smiles>

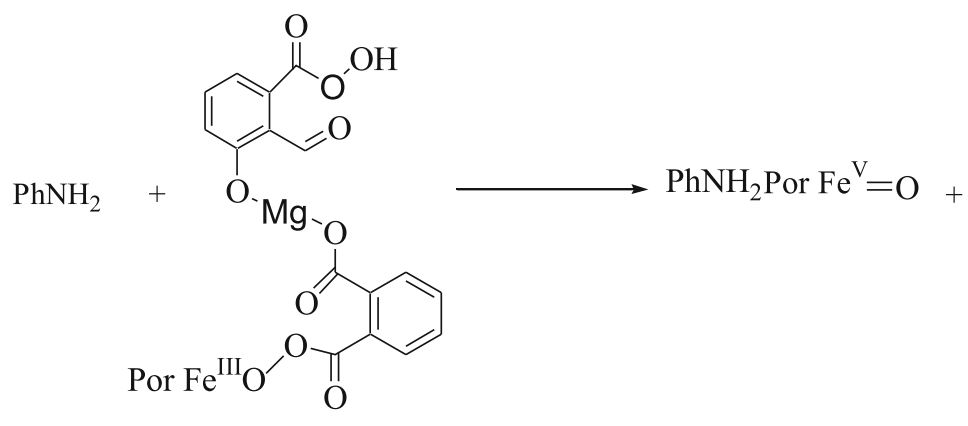<smiles>COC(=O)c1ccccc1C(=O)[O-]</smiles><smiles>COC(=O)c1ccccc1C(=O)[O-]</smiles>

$\mathrm{PhNO}+\mathrm{PhNH}_{2} \longrightarrow \mathrm{PhN}=\mathrm{NPh}+\mathrm{H}_{2} \mathrm{O}$ present study has no parallel ${ }^{17}$. The lack of free energy involved in the reaction. In the literature study ${ }^{24}$ also

\section{Mechanism}<smiles>COC(=O)c1ccccc1C(=O)OO[Ga]=[Pt]</smiles>

rature $(335.7 \mathrm{~K})$ falls out of the experimental range of temperature. The same possibilities were reported by Elango and Buvaneswari ${ }^{16}$. Operation of inductive and resonance effect opposing each other is known but the relationship can be explained only by the compensation effect. Aniline in basic and neutral media is present as free bases but in acid medium exists in dual forms, the free bases and conjugate acids ${ }^{17}$. The stoichiometry of the findings shows that two aniline molecules were the oxidation involves two aniline molecules in the rate determining step. This shows that the catalyst-aniline complex is likely to be the electrophile and free aniline may be the nucleophile. The influence of the substituents on the reactivity of the nucleophile is approximately compensated by the influence of the same substituent on the reactivity of the electrophile ${ }^{17}$. In some of the substituted aniline exact compensation is doubtful and the resultant effect is experienced on the oxidation rate.

The addition of acrylonitrile monomer showed no variation in the reaction rate and no formation of turbidity (no formation of polymer) in the oxidation of aniline. 
This indicates the absence of free radical mechanism in this oxidation reaction. So the ionic reaction was chosen in this oxidation study. Generally, the enhancement of the electrophillic activity of peroxide will minimize the importance of undesirable free radical pathways, resulting in a mixture of products ${ }^{25}$. Usually peroxy ions act as strong nucleophiles. The investigation results illustrate a fascinating note that the increase of $\mathrm{H}^{+}$retards the rate of the reaction. With a decrease of $\mathrm{pH}$ the molecule gains a proton, becomes less negatively charged and hence the rate of the reaction decreases ${ }^{26}$. In the fourth step of the following mechanism the dianion consumes two protons, becomes less negative charged and hence the rate of the reaction decreases. Based on the above experimental results, the following reactions (scheme 1) are suggested to constitute the most probable mechanism of the reaction.

\section{CONCLUSION}

Kinetics of the oxidation of aniline by meso-tetraphenylporphyriniron(III) chloride is fractional order with respect to the substrate, first order with respect to the oxidant and first order with respect to the catalyst .The addition of $\mathrm{H}^{+}$suppresses the rate of the reaction. Simple and multiple linear correlation of the rate constants with substituent parameters was found to be ineffective. Correlation of the experimental data of solvent reveals that solvent interaction plays a major role in leading the reactivity. The formation of charged intermediate compound was supported by the high negative values of entropy of activation and UV-spectrum. A most probable mechanism has been proposed for the meso-tetraphenylporphyriniron(III) chloride catalyzed oxidation of anilines by magnesium monoperoxyphthalate. The strength of isokinetic relationship and thermodynamic relationships has been tested and discussed. With magnesium monoperoxyphthalate as oxygen donor, the first generation catalyst ironporphyrin, is proved to be a more effective catalyst in oxidising aniline.

\section{LITERATURE CITED}

1. Xian-Tai Zhou, Hong-Bing Ji \& Qiu-Lan Yuan. (2008). Baeyer-Villiger oxidation of ketones catalyzed by iron(III) meso-tetraphenylporphyrin chloride in the presence of molecular oxygen J. Porphyr. Phthalocya., 12, 94-100. DOI: 10.1142/ S1088424608000121.

2. Amit Singh, Arunava Agarwala, Kaliappan Kamaraj \& Debkumar Bandyopadhyay. (2011). The mechanistic aspects of iron(III) porphyrin catalyzed oxidation reactions in mixed solvents Inorganica Chimica Acta 372, 295-303. DOI:10.1016/j. ica.2011.02.054.

3. Ned A. Stephenson \& Alexis, T. Bell. (2007), Mechanistic insights into iron porphyrin-catalyzed olefin epoxidation by hydrogen peroxide: Factors controlling activity and selectivity J. Mol. Catal. A-Chem., 275, 54-62. DOI:10.1016/j.molcata.2007.05.005

4. Masami Fukushima \& Kenji Tatsumi (2006), Complex formation of water-soluble iron(III)-porphyrin with humic acids and their effects on the catalytic oxidation of pentachlorophenol J. Mol. Catal. A-Chem., 245, 178-184. DOI:10.1016/j. molcata.2005.09.051

5. Masami Fukushima (2008), Oxidative degradation of pentachlorophenol by an iron(III)-porphyrin catalyst bound to humic acid via formaldehyde polycondensation J. Mol. Catal. A-Chem., 286, 47-54. DOI:10.1016/j.molcata.2008.01.041

6. Genebaldo, S. Nunes, Ildemar Mayer, Henrique, E. Toma \& Koiti Araki. (2005) J. of catalysis, 236, 55-61. Kinetics and mechanism of cyclohexane oxidation catalyzed by supramolecular manganese(III) porphyrins. DOI: 10.1016/j.jcat.2005.09.003.

7. Ned A. Stephenson \& Alexis, T. Bell. (2006), The influence of substrate composition on the kinetics of olefin epoxidation by hydrogen peroxide catalyzed by iron(III) [tetrakis(pentafluorophenyl)] porphyrin. J. Mol. Catal. A-Chem., 258, 231-235. DOI: 10.1016/j.molcata.2006.05.034.

8. Amit Singh, Arunava Agarwala, Kaliappan Kamaraj \& Debkumar Bandyopadhyay. (2011). The mechanistic aspects of iron(III) porphyrin catalyzed oxidation reactions in mixed solvents. Inorganica Chimica Acta., 372, 295-303. DOI: 10.1016/j. ica.2011.02.054.

9. Tollari, S., Fumagalli, A. \& Porta, F. (1996). Catalytic Oxidation of Benzylic Amines to Imines by M (TPP)CL(M = $\mathrm{Fe}, \mathrm{Mn}$ ) followed by Reduction to Secondary Amines. Inorg. Chim. Acta., 247, 71-80. DOI : 10.1016/0020-1693(95)04836-7.

10. Qingzhang Lu, Ruqin Yu \& Guoli Shen. (2003). The Structure, Catalytic Activity and Reaction Mechanism Modeling for Halogenated Iron-Tetraphenylporphyrin complexes. J. Mol. Catal. A-Chem., 198, 9-19 DOI: 10.1016/S 13811169(02)00726-4.

11. Fabiana C Skrobot, Ieda Rosa LV, Ana Paula A. Marques, Patricia, R. Martins, Rocha, J., Anabela A. Valente \& Yassuko Iamamoto. (2005). Asymmetric cationic methyl pyridyl and pentafluorophenyl porphyrin encapsulated in zeolites: A cytochrome P-450 model. J. Mol. Catal. A-Chem., 237, 86-92. DOI: 10.1016/j.molcata.2005.05.001.

12. Enrico Baciocchi, Osvaldo Lanzalunga \& Andrea Lapi. (1995). Formation of quinones in the iron porphyrin catalyzed oxidation of benzene and alkylbenzenes by magnesium monoperoxyphthalate. Tetrahedron lett., 36, 3547-3548. DOI: 10.1016/0040-4039(95)00554-P.

13. Simon J. Hayes, David W. Knight, Andrew W.T. Smith, \& Mark J. O'Halloran (2010). On the curious oxidations of 2-furylethanols. Tetrahedron lett., 51, 720-723. DOI:10.1016/j. tetlet.2009.11.119.

14. Lisa, Y. Wu, Joseph, K. Choi, Krit, Y. Hatton, Clifford E. Berkman (2010). A simple method for the oxidation of a-amino acid esters to a-oximino esters. Tetrahedron lett., 51, 402-403. DOI:10.1016/j.tetlet.2009.11.045.

15. Bhuvaneshwari, D.S. (2008). Solvent Hydrogen Bonding and Structural Influences on the reactivity of Anilines. Ph.D thesis, Gandhigram Rural University Gandhigram, India.

16. Bhuvaneshwari, D.S. \& Elango, K.P. (2006). Correlation analysis of reactivity in the oxidation of anilines by nicotinium dichromate in nonaqueous media. Int. J. Chem. Kinet., 38, 657-665. DOI 10.1002/kin.20199.

17. Karunakaran, C. \& Palanysamy, P.N. (1999). Lack of linear free energy relationship: tungsten(VI) catalyzed of anilines. Int. J. Chem. Kinet., 31, 571-575. DOI: 10.1002/(SICI)1097-4601.

18. Bhuvaneshwari, D.S. \& Elango, K.P. (2006). Preferential solvation effects on the kinetics and thermodynamics of oxidation by chromium (IV). Z. Phys. Chem., 220, 697-721. DOI 10.1524/zpch.2006.220.6.697.

19. Karunakaran, C. \& Palanysamy, P.N. (2001). Autocatalysis in the sodium perborate oxidation of aniline in acetic acid-ethylene glycol. J. Mol. Catal. A-Chem., 172, 9-17. DOI. org/10.1016/S1381-1169(01)00113-3.

20. Bhuvaneshwari, D.S. \& Elango, K.P. (2006). Studies on the kinetics of imidazolium fluorochromate oxidation of some meta- and para-substituted anilines in nonaqueous media. Int. J. Chem. Kinet., 38, 166-175. DOI: 10.1002/ kin.20150.

21. Chockalingam Karunakaran \& Ramasamy Kamalam. (2002).Mechanism and reactivity in perborate oxidation of anilines in acetic acid. J. Chem. Soc., Perkin Trans., 2, 20112018.DOI:10.1039/b208199g. 
22. Durvas Bhuvaneswari, S. \& Kuppanagounder Elango, P. (2005). Effect of Preferential Solvation on the Kinetics and Thermodynamics of Oxidation of Anilines by Nicotinum dichromate. Z.Naturforsch. 60b, 1105-1111.

23. Corwin Hansch, Leo, A. \& Taft, R.W. (1991). A Survey of Hammett Substituent Constants and Resonance and Field Parameters Chem. Rev., 91, 165-195.DOI: 10.1021/cr00002a004.

24. Subbiah Meenakashisundaram, Selvaraju, M. Made Gowda, N.M., Kanchugarakoppal, Rangappa, S. (2005). Effect of substituents on the rate of oxidation of anilines with peroxomonosulfate monoanion (HOOSO-3) in aqueous acetonitrile: a mechanic study. Int. J. chem. kinet.37, 649-657. DOI:10.1002/kin.20119.

25. Chandramohan, G., Kalyansundharam, S. \& Renganathan, R. (2002). Oxidation of indole -3-acetic acid by peroxomonosulphate: A kinetic and mechanic study. Int. J. Chem. Kinet., 34, 569. DOI:10.1002/kin.10060.

26. Kutti Rani, S., Nirmal Kumar, S., Crystal Y Wilson, Gopi, A. \& Eswaramoorthy, D. (2009). Oxidation of Vallillin by Peroxomonosulphate-Thermodynamic and kinetics Investigation. J. Ind. Eng. Chem., 15, 898-901. DOI: 10.1016/j. jiec.2009.09.020. 